\title{
The Effect of Exercise on the Cardiovascular Risk Factors Constituting the Metabolic Syndrome
}

\author{
A Meta-Analysis of Controlled Trials
}

\author{
Nele Pattyn • Véronique A. Cornelissen • \\ Saeed R. Toghi Eshghi $\cdot$ Luc Vanhees
}

Published online: 19 December 2012

(c) The Author(s) 2012. This article is published with open access at Springerlink.com

\begin{abstract}
Background Numerous meta-analyses have investigated the effect of exercise in different populations and for single cardiovascular risk factors, but none have specifically focused on the metabolic syndrome (MetS) patients and the concomitant effect of exercise on all associated cardiovascular risk factors.

Objective The aim of this article was to perform a systematic review with a meta-analysis of randomized and clinical controlled trials (RCTs, CTs) investigating the effect of exercise on cardiovascular risk factors in patients with the MetS.

Methods RCTs and CTs $\geq 4$ weeks investigating the effect of exercise in healthy adults with the MetS and published in a peer-reviewed journal up to November 2011 were included. Primary outcome measures were changes in waist circumference (WC), systolic and diastolic blood pressure, high-density lipoprotein cholesterol (HDL-C), triglycerides and fasting plasma glucose. Peak oxygen uptake $\left(\dot{V} \mathrm{O}_{2 \text { peak }}\right)$ was a secondary outcome. Random and fixed-effect models were used for analyses and data are reported as means and 95\% confidence intervals (CIs).

Results Seven trials were included, involving nine study groups and 206 participants (128 in exercise group and 78 in control group). Significant mean reductions in WC -3.4 $(95 \%$ CI $-4.9,-1.8) \mathrm{cm}$, blood pressure -7.1 (95\% CI $-9.03,-5.2) /-5.2(95 \% \mathrm{CI}-6.2,-4.1) \mathrm{mmHg}$ and a
\end{abstract}

N. Pattyn and V. A. Cornelissen are joint first authors.

N. Pattyn $(\bowtie)$ • V. A. Cornelissen · S. R. T. Eshghi ·

L. Vanhees

Department of Rehabilitation Sciences, KU Leuven, B 1501,

Tervuursevest 101, 3001 Louvain, Belgium

e-mail: neleke_pattyn@hotmail.com significant mean increase in HDL-C $+0.06(95 \% \mathrm{CI}+0.03$, $+0.09) \mathrm{mmol} / \mathrm{L}$ were observed after dynamic endurance training. Mean plasma glucose levels -0.31 (95\% CI $-0.64,0.01 ; \mathrm{p}=0.06) \mathrm{mmol} / \mathrm{L}$ and triglycerides -0.05 $(95 \% \mathrm{CI}-0.20,0.09 ; \mathrm{p}=0.47) \mathrm{mmol} / \mathrm{L}$ remained statistically unaltered. In addition, a significant mean improvement in $\dot{V} \mathrm{O}_{2 \text { peak }}$ of $+5.9(95 \% \mathrm{CI}+3.03,+8.7) \mathrm{mL} / \mathrm{kg} / \mathrm{min}$ or $19.3 \%$ was found.

Conclusions Our results suggest that dynamic endurance training has a favourable effect on most of the cardiovascular risk factors associated with the MetS. However, in the search for training programmes that optimally improve total cardiovascular risk, further research is warranted, including studies on the effects of resistance training and combined resistance and endurance training.

\section{Introduction}

The 'metabolic syndrome' (MetS) or 'syndrome $\mathrm{X}$ ' is a constellation of cardiovascular risk factors including abdominal obesity, impaired glucose control, hypertension and dyslipidaemia [1]. The MetS components separately increase the risk for cardiovascular disease (CVD) and allcause mortality, but the full syndrome is associated with an increase in risk that is greater than the risk of each separate risk factor [2]. Therapeutic lifestyle changes, including exercise, are recommended as firstline strategy in the treatment of cardiovascular risk factors [3]. Previous metaanalyses demonstrated that dynamic endurance exercise decreases blood pressure (BP) in hypertensive individuals $[4,5]$, causes a significant reduction in blood lipids and lipoproteins in patients with hyperlipidaemia [6,7], reduces glycated haemoglobin $\left(\mathrm{HbA}_{1 \mathrm{c}}\right.$; percentage) in patients with type 2 diabetes mellitus [7] and is associated with improved 
body composition in obese individuals [7]. However, to the best of the authors' knowledge, meta-analyses have not been performed to determine the concomitant effect of exercise on all risk factors of the MetS in patients with the MetS.

Therefore, the aim of this study was to perform a systematic review with a meta-analysis of RCTs or CTs investigating the effect of exercise on cardiovascular risk factors in patients with the MetS.

\section{Research Design and Methods}

\subsection{Literature Search}

We conducted a systematic literature search with the MEDLINE computerized database from its inception to November 2011 using the following medical subject headings (MeSH terms): 'Metabolic Syndrome X' AND ('Exercise' OR 'Motor Activities'). A second literature search was done in MEDLINE using the following title terms: 'Metabolic Syndrome' OR 'Syndrome X' AND 'Exercise'. In addition, the reference lists from published original and review articles were searched manually to identify other possible eligible studies.

\subsection{Inclusion Criteria}

We included studies in the meta-analysis if the following requirements were met: (i) (RCTs) or CTs investigating the effect of exercise (dynamic endurance exercise-dynamic resistance exercise-or a combination); (ii) the duration of intervention was at least 4 weeks; (iii) intervention in adults ( $\geq 18$ years) with the MetS (WHO 1998 [8], National Cholesterol Education Program Adult Treatment Panel III [NCEP/ATP III] 2001 [9] or International Diabetes Federation [IDF] 2005 [10]) but with no other CVD; (iv) full publication in a peer-reviewed journal up to November 2011.

\subsection{Measured Outcomes}

The primary outcomes were changes in cardiovascular risk factors associated with the MetS: i.e. waist circumference (WC), fasting plasma glucose, systolic and diastolic blood pressure (SBP, DBP), high-density lipoprotein cholesterol (HDL-C) and triglycerides. Secondary outcomes included peak oxygen uptake ( $\left.\dot{V} \mathrm{O}_{2 \text { peak }}\right)$, body weight, body mass index (BMI), fat mass, total cholesterol, low-density lipoprotein cholesterol (LDL-C) and plasma insulin.

\subsection{Data Extraction}

Two unblinded reviewers (N.P. and S.R.T.E.) independently conducted data extraction. A specifically developed data extraction sheet was used to extract data on study source, study design, characteristics of the participants, the exercise characteristics and the different outcomes in each study. Disagreements were solved by consensus or by a third reviewer (V.C.).

\subsection{Study Quality}

Study quality was assessed using an adapted Physiotherapy Evidence Database (PEDro) scale [11], which is an 11-item questionnaire designed to collect data on eligibility criteria, random allocation, concealed allocation, similarity of baseline values, blinding of therapists and/or assessors, key outcomes, intent-to-treat analysis, between group differences, and point and variability measures. We regarded the quality criteria 'blinding of participants' and 'blinding of therapists' as not applicable in exercise intervention studies, and omitted both criteria. All questions were binary (yes [1] or no [0]). The minimum score was 0 and the maximum was 9 , with a higher number reflecting a better study quality. The PEDro-scale has been reported to be valid and reliable $[12,13]$.

\subsection{Statistical Analysis}

Statistical analyses were performed using $\mathrm{SAS}^{\circledR}$ version 9.3 (SAS Institute, Cary, NC, USA) and Review Manager Software (RevMan 5.1; Cochrane Collaboration, Oxford, UK). Descriptive data are reported as mean \pm standard deviation (SD) or median and range. The mean baseline values were calculated by combining mean values from the intervention and control groups, weighted by the total number of participants in each study group. Since we worked with continuous data, we took the approach of assuming that randomization would adjust for baseline differences and used endpoint data only in the meta-analytical statistics. Each effect was weighted by the inverse of its variance. The results were combined using fixed and random effect models and presented with $95 \%$ confidence intervals (CI). Heterogeneity between trial results was tested with a standard Chi-squared $\left(\chi^{2}\right)$ test. The $\mathrm{I}^{2}$ parameter was used to quantify any inconsistency $\left(\mathrm{I}^{2}=[(\mathrm{Q}-\mathrm{df})] \times 100 \%\right.$, where $\mathrm{Q}$ is the $\chi^{2}$ statistic and df are the degrees of freedom). A value for $\mathrm{I}^{2}>50 \%$ has been considered to be substantial heterogeneity. To examine the influence of each study on the overall results, analyses were also performed with each study deleted from the model. In addition, we performed a simple metaregression analysis to investigate whether changes in the primary outcomes were related to changes in WC. Twosided tests for overall effects were considered significant at $\mathrm{p} \leq 0.05$. Finally, funnel plots were used to assess the potential of small publication bias. 


\section{Results}

\subsection{Literature Search}

From 822 potentially relevant studies retrieved from our search, 9 trials met our inclusion criteria [14-22]. A flow diagram of literature search and selection is presented in Fig. 1. Two studies were a duplicate of another study, i.e. using the same population and intervention, and so we included the most complete publication $[17-19,22]$. Hence, seven trials were included in the final analysis. Some of the trials applied different training regimens [17, 18] so that a total of nine dynamic endurance training interventions, one dynamic resistance training group and two combined dynamic endurance/resistance training groups were available for qualitative analysis. We used the meta-analytic techniques only on the nine dynamic endurance training groups.

\subsection{Characteristics of the Participants and Study Designs}

Characteristics of the 12 included intervention groups are summarized in Table 1. All studies were published between 2003 and 2010. Five of them were RCTs [15, 17, $18,20,21]$ and two of them were CTs $[14,16]$. Diagnosis of the MetS was based on WHO [8] criteria [14, 18], ATP III [9] criteria [16] or IDF [10] criteria [17, 20, 21]. One trial [15] used a mixture of the three definitions i.e. stage 1 or 2 hypertension (SBP $140-159$ or $\geq 160 \mathrm{mmHg}$; DBP 90-99 or $\geq 100 \mathrm{mmHg}$ ); plasma insulin concentration greater than $80 \mu \mathrm{U} / \mathrm{mL}(>556 \mathrm{pmol} / \mathrm{L}) 2 \mathrm{~h}$ after the ingestion of $75 \mathrm{~g}$ of glucose; dyslipidaemia, defined as high triglyceride $(\geq 150 \mathrm{mg} / \mathrm{dL} ; \geq 1.7 \mathrm{mmol} / \mathrm{L})$ and/or low HDL-C levels (men $\leq 40 \mathrm{mg} / \mathrm{dL} ; \leq 1.04 \mathrm{mmol} / \mathrm{L}$, women $\leq 50 \mathrm{mg} / \mathrm{dL} ; \leq 1.3 \mathrm{mmol} / \mathrm{L}$ ).

272 participants were randomized or allocated to an exercise group (dynamic endurance training, $\mathrm{n}=147$; dynamic resistance training, $\mathrm{n}=11$; combination, $\mathrm{n}=32$ ) or a control group $(n=82)$. Average drop out was $10 \%$ (range 0-33\%), resulting in a total of 245 participants that could be included in the final analysis: 128 of them completed a dynamic endurance training intervention, 10 completed a dynamic resistance training intervention, 30 completed a combined intervention and 78 were control subjects.

Median age was 52 years (range 46-64). Six study trials included both men and women, and one trial included only women [17] ( $\pm 38 \%$ and $\pm 41 \%$ males in the exercise and control group, respectively) [15]. Four trials defined 'not being sedentary' as an exclusion criterion [14-17], while this was not specifically reported in the other three trials $[18,20,21]$. Two trials did not report on diabetes status, four study trials excluded individuals with diabetes [14-17] whereas Balducci et al. [20] included only MetS patients with diabetes. The use of medication was reported in three trials [18, 20, 21]; antihypertensive agents, lipid-lowering agents and oral hypoglycaemic agents or insulin use were
Fig. 1 Prisma 2009 flow diagram

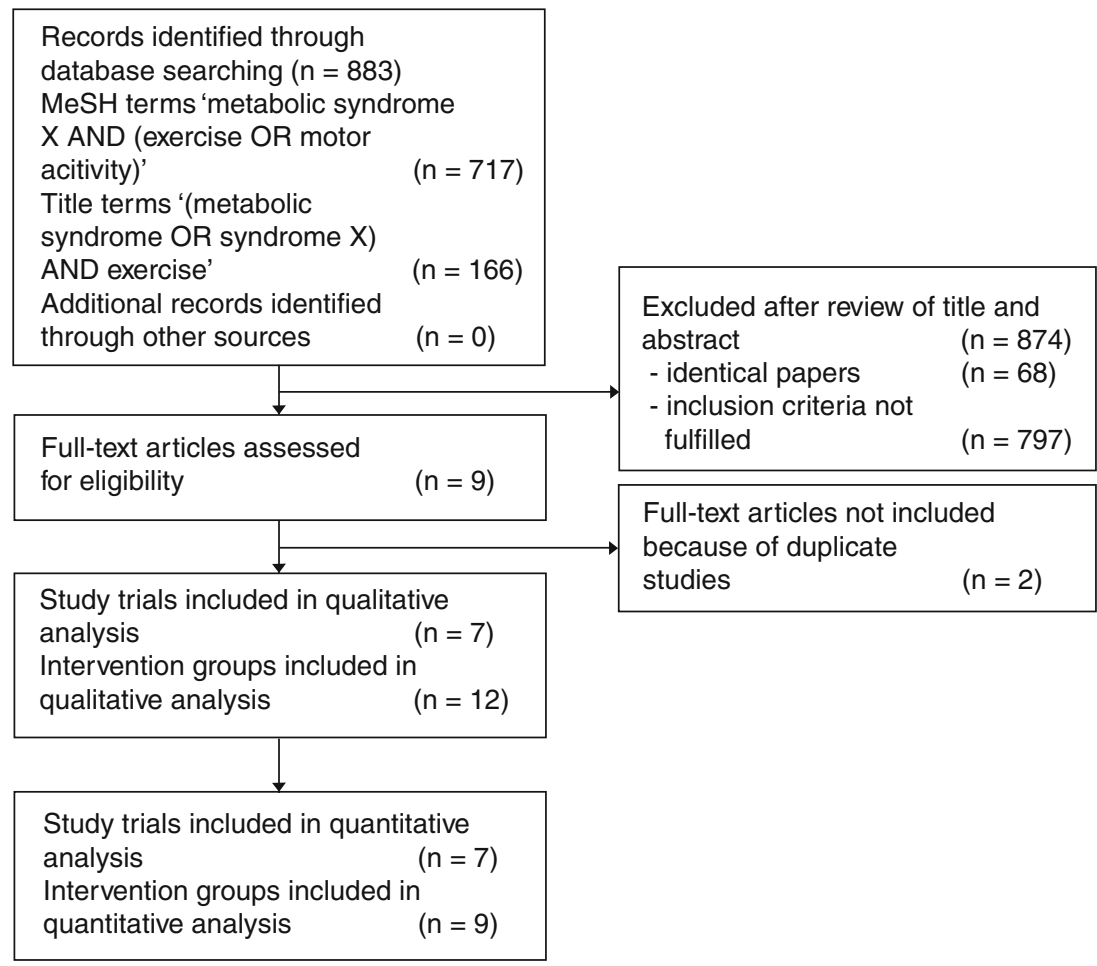




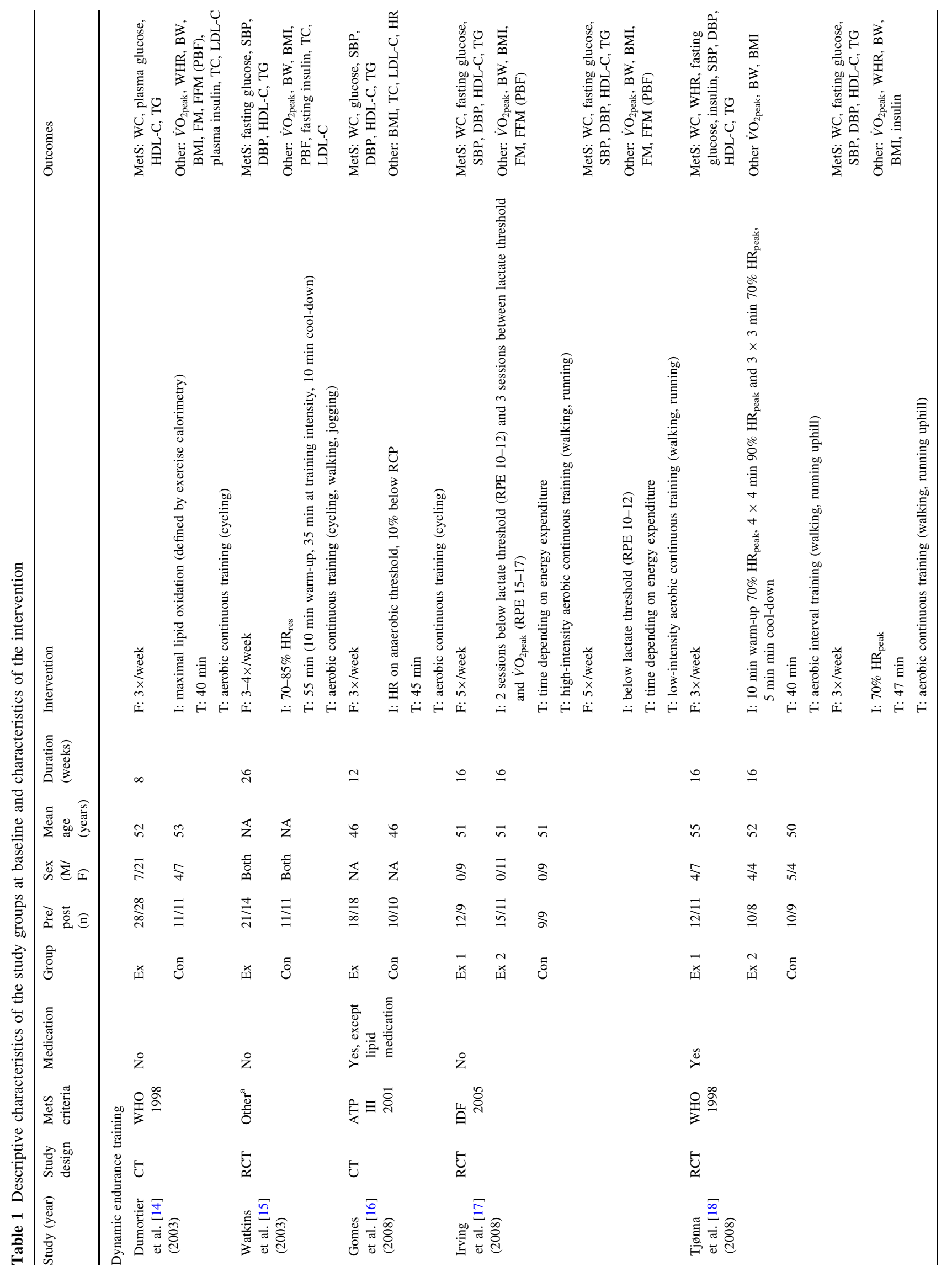




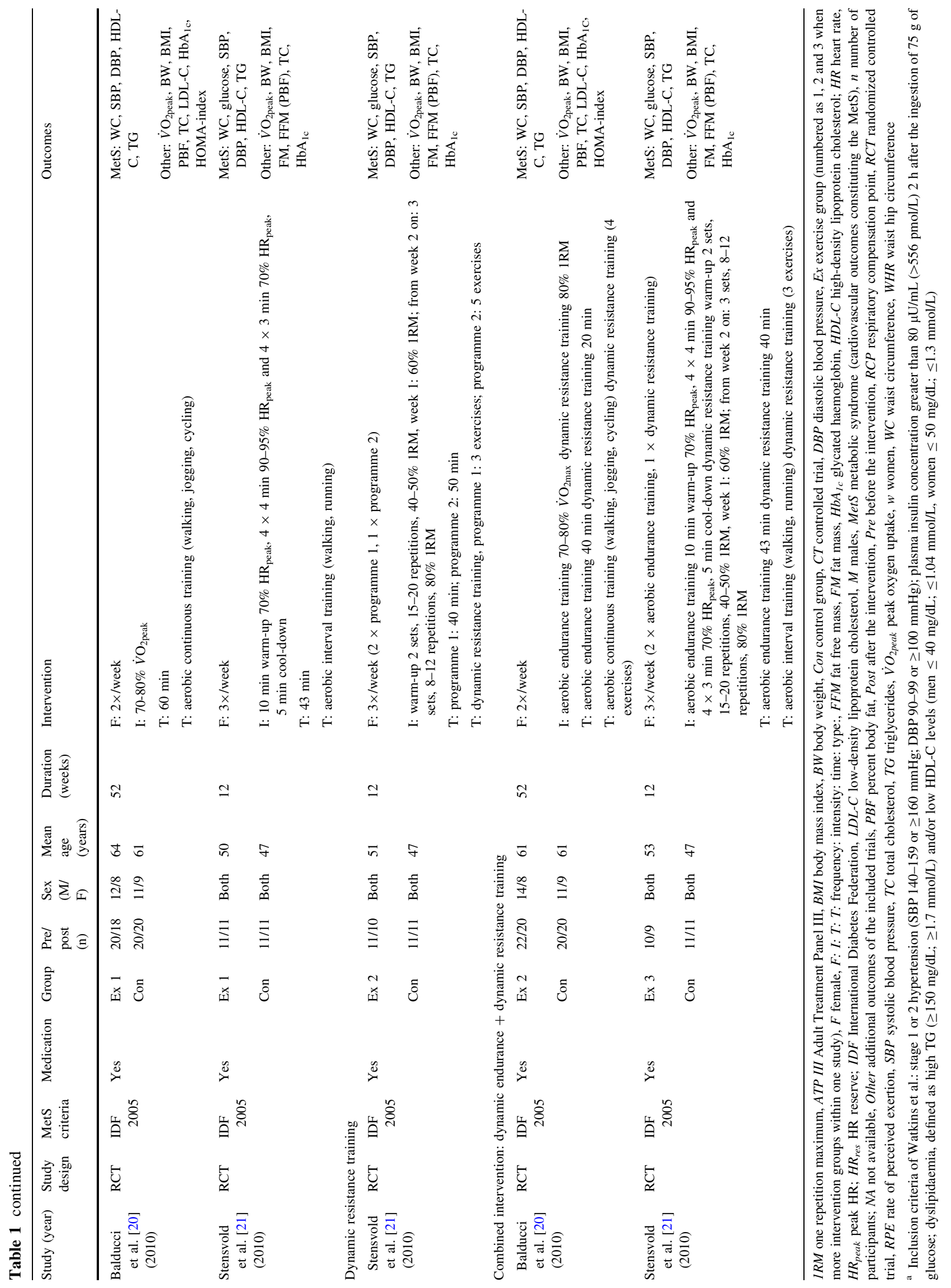




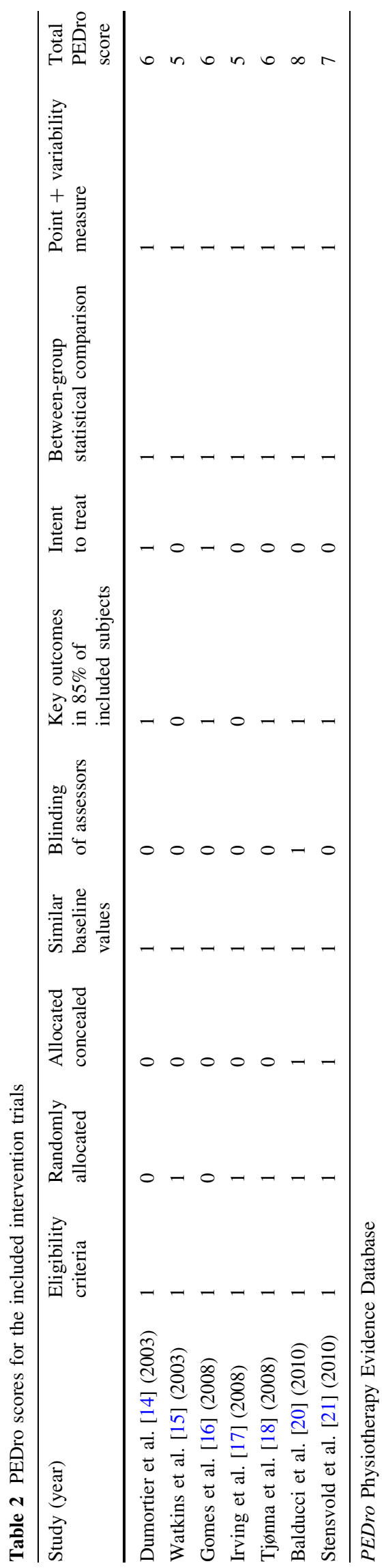

common pharmacotherapy treatments. Three other trials defined the use of medications as an exclusion criterion [14, 15, 17]. Gomes et al. [16] defined drugs known to affect lipoprotein metabolism as an exclusion criterion.

The 12 interventions lasted between 8 and 52 weeks (median 16). The frequency of training varied between two and five training sessions weekly (median 3 ), with an average of $47.5 \mathrm{~min}$ per session (range 40-60). All trials used walking, jogging or cycling as the modes of exercise. Two dynamic endurance training groups performed interval training [18, 21], while the other seven endurance training groups reported using a continuous training programme. Intensities ranged from moderate (e.g. 'maximal lipid oxidation') to high (e.g. intervals at $90-95 \%$ of heart rate peak $\left.\left[\mathrm{HR}_{\text {peak }}\right]\right)$. The exercise programmes were supervised in all studies except for Dumortier et al. [14] where only the first training sessions were supervised and the patients continued the training at home afterwards.

In Table 2, the results of the adapted PEDro-scale are represented. The median PEDro score was 6 , with a range from $5[15,17]$ to 8 [20].

\subsection{Primary Outcomes: Effect of Exercise on Cardiovascular Risk Factors Associated with the Metabolic Syndrome}

Dynamic endurance training resulted in a mean reduction in WC of $3.36 \mathrm{~cm}$ (Fig. 2; baseline 104.62; 95\% CI -4.87 , $-1.84 ; \mathrm{p}<0.0001 ; \mathrm{I}^{2}=35 \%$ ), a mean BP decrease of 7.11 (Fig. 3; baseline 137.97; 95\% CI -9.03, -5.18; $\mathrm{p}<0.0001 ; \mathrm{I}^{2}=0 \%$ ) $\mathrm{mmHg} / 5.15 \mathrm{mmHg}$ (Fig. 4; baseline 87.60; 95\% CI $\left.-6.16,-4.13 ; \mathrm{p}<0.0001 ; \mathrm{I}^{2}=28 \%\right)$ and a mean increase in HDL-C of 0.06 (Fig. 5; baseline 1.04; $\left.95 \% \mathrm{CI}+0.03,+0.09 ; \mathrm{p}<0.0001 ; \mathrm{I}^{2}=38 \%\right) \mathrm{mmol} / \mathrm{L}$. By contrast, levels of triglycerides (Fig. 6; -0.05 ; baseline $2.05 ; 95 \%$ CI $\left.-0.20,+0.09 ; \mathrm{p}=0.47 ; \mathrm{I}^{2}=0 \%\right) \mathrm{mmol} / \mathrm{L}$ and plasma glucose (Fig. 7; -0.31 ; baseline $5.98 ; 95 \% \mathrm{CI}$ $\left.-0.64,+0.01 ; \mathrm{p}=0.06 ; \mathrm{I}^{2}=0 \%\right) \mathrm{mmol} / \mathrm{L}$ remained statistically unaltered.

To assess the effect of individual dynamic endurance studies on the summary estimate we performed a sensitivity analysis, in which the pooled estimates for the different outcomes were recalculated omitting one or two studies at a time. When we excluded the two aerobic interval training (AIT) studies, results were similar. However, when we omitted the only trial in which all patients had type 2 diabetes [17], overall changes in DBP, HDL-C and WC were no longer statistically significant $(\mathrm{p}=0.07$; $\mathrm{p}=0.44 ; \mathrm{p}=0.40$, respectively).

The results of the meta-regression showed that decreases in DBP were significantly associated with reductions in WC $(r=0.91 ; p=0.001)$. A non-significant trend was found for the association of WC with SBP $(r=0.67$; 


\begin{tabular}{lcc} 
& Mean Difference & \\
Study or Subgroup & IV, Fixed, 95\% Cl & Yea \\
\hline Dumortier et al. [14] & $-7.60[-20.03,4.83]$ & 2003 \\
Gomes et al. [16] & $3.00[-3.56,9.56]$ & 2008 \\
Irving et al. [17] A & $0.60[-11.10,12.30]$ & 2008 \\
Irving et al. [17] B & $5.10[-5.84,16.04]$ & 2008 \\
Tjønna et al. [18] A & $-11.50[-22.89,-0.11]$ & 2008 \\
Tjønna et al. [18] B & $-12.90[-26.90,1.10]$ & 2008 \\
Stensvold et al. [21] & $-2.10[-10.53,6.33]$ & 2010 \\
Balducci et al. [20] & $-3.70[-5.36,-2.04]$ & 2010 \\
& & \\
Total (95\% Cl) & $-3.36[-4.87,-1.84]$ & \\
Heterogeneity: $\chi^{2}=10.78$, df $=7(p=0.15) ; I^{2}=35 \%$ & \\
Test for overall effect: $Z=4.35(p<0.0001)$ &
\end{tabular}

Fig. 2 Average net changes and corresponding 95\% confidence intervals for waist circumference. Tjønna et al. [18] $A$ and $B$ represents moderate continuous training programme and aerobic interval training programme, respectively; and Irving et al. [17] $A$ and $B$ represents
Mean Difference

IV, Fixed, $95 \% \mathrm{Cl}$

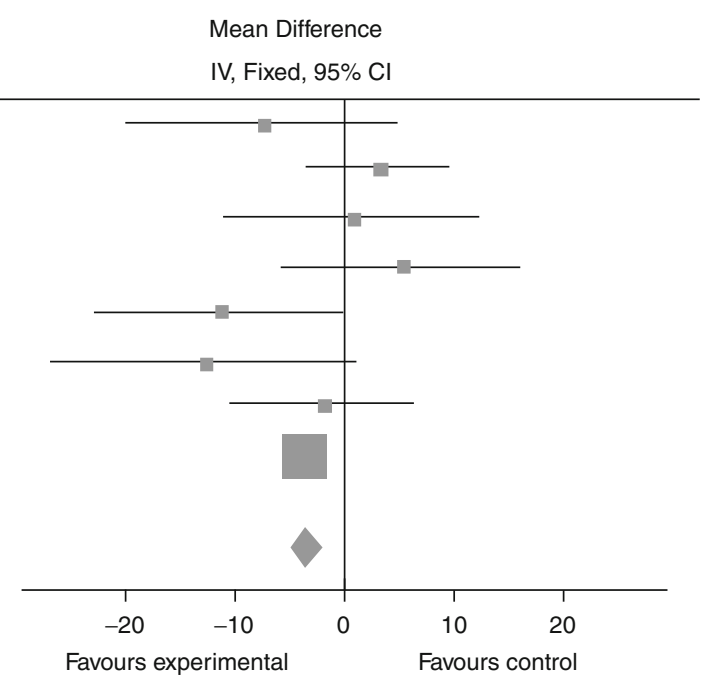

high-intensity training and low-intensity training, respectively. $C I$ confidence intervals, $d f$ degrees of freedom, $I V$ intervention, $\chi^{2}$ Chisquared

\begin{tabular}{lll} 
& \multicolumn{1}{c}{ Mean Difference } \\
Study or Subgroup & \multicolumn{1}{c}{ IV, Fixed, 95\% Cl } & Year \\
\hline Watkins et al. [15] & $-5.00[-14.60,4.60]$ & 2003 \\
Gomes et al. [16] & $-3.00[-9.56,3.56]$ & 2008 \\
Irving et al. [17] A & $-7.00[-21.57,7.57]$ & 2008 \\
Irving et al. [17] B & $-6.00[-19.78,7.78]$ & 2008 \\
Tjønna et al. [18] A & $-6.00[-22.40,10.40]$ & 2008 \\
Tjønna et al. [18] B & $-20.00[-37.67,-2.33]$ & 2008 \\
Stensvold et al. [21] & $-7.90[-24.43,8.63]$ & 2010 \\
Balducci et al. [20] & $-7.50[-9.66,-5.34]$ & 2010 \\
& & \\
Total (95\% Cl) & $-7.11[-9.03,-5.18]$ & \\
Heterogeneity: $\chi^{2}=3.91$, df $=7(p=0.79) ; I^{2}=0 \%$ & \\
Test for overall effect: $Z=7.23(p<0.00001)$
\end{tabular}

Fig. 3 Average net changes and corresponding 95\% confidence intervals for systolic blood pressure. Tjønna et al. [18] $A$ and $B$ represents moderate continuous training programme and aerobic interval training programme, respectively; and Irving et al. [17] $A$ and

$\mathrm{p}=0.10)$ and for WC with HDL-C $(\mathrm{r}=-0.68 ; \mathrm{p}=$ $0.06)$. triglyceride and plasma glucose were not related to changes in WC ( $p>0.20$ for all).

Only one study investigated the effect of dynamic resistance training on components of the MetS [21]. They reported a significant reduction of WC (from mean \pm SD $111.5 \pm 10.8$ to $110.1 \pm 11.0 \mathrm{~cm} ; \mathrm{p}<0.05)$ whereas HDL-C, triglycerides, plasma glucose, SBP and DBP remained statistically unaltered $(\mathrm{p}>0.05$ for all).
$B$ represents high-intensity training and low-intensity training, respectively. $C I$ confidence intervals, $d f$ degrees of freedom, IV intervention, $\chi^{2}$ Chi-squared

Two trials, involving 33 participants investigated the effect of combined dynamic endurance and dynamic resistance training in patients with the MetS [20, 21]. Both trials observed a significant reduction of WC. In addition, Balducci et al. [20] reported positive findings for $\mathrm{HbA}_{1 \mathrm{c}}$ (from mean $\pm \mathrm{SD} 7.29 \pm 1.35$ to $6.34 \pm 0.96 \%$; $\mathrm{p}<0.0001$ ) and HDL-C (from mean $\pm \mathrm{SD} 44.1 \pm 2.0$ to $47.6 \pm 1.85 \mathrm{mg} / \mathrm{dL} ; \mathrm{p}<0.001)$ whereas this remained statistically unaltered in the study of Stensvold et al. [21]. 


\begin{tabular}{lcc} 
& $\begin{array}{c}\text { Mean Difference } \\
\text { IV, Fixed, 95\% Cl }\end{array}$ & Year \\
\hline Study or Subgroup & $-4.00[-8.90,0.90]$ & 2003 \\
\hline Watkins et al. [15] & $1.00[-4.61,6.61]$ & 2008 \\
Gomes et al. [16] & $-2.00[-10.62,6.62]$ & 2008 \\
Irving et al. [17] A & $2.00[-7.88,11.88]$ & 2008 \\
Irving et al. [17] B & $-7.00[-19.05,5.05]$ & 2008 \\
Tjønna et al. [18] A & $-14.00[-26.89,-1.11]$ & 2008 \\
Tjønna et al. [18] B & $-4.50[-13.53,4.53]$ & 2010 \\
Stensvold et al. [21] & $-5.50[-6.58,-4.42]$ & 2010 \\
Balducci et al. [20] & \\
& & \\
Total (95\% Cl) & $-5.15[-6.16,-4.13]$ & \\
Heterogeneity: $\chi^{2}=9.67$, df $=7(p=0.21) ; I^{2}=28 \%$ & \\
Test for overall effect: $Z=9.96(p<0.00001)$
\end{tabular}

Fig. 4 Average net changes and corresponding 95\% confidence intervals for diastolic blood pressure. Tjønna et al. [18] $A$ and $B$ represents moderate continuous training programme and aerobic interval training programme, respectively; and Irving et al. [17] $A$ and
Mean Difference

IV, Fixed, $95 \% \mathrm{Cl}$

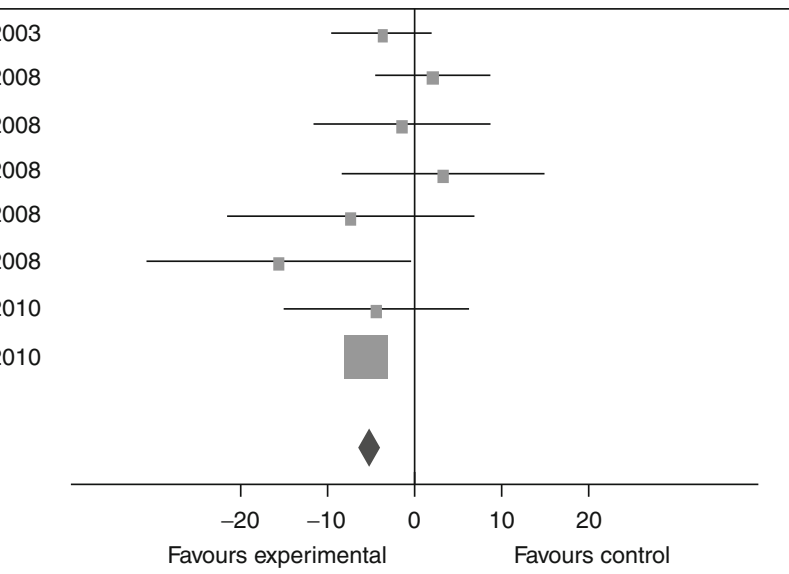

$B$ represents high-intensity training and low-intensity training, respectively. $C I$ confidence intervals, $d f$ degrees of freedom, $I V$ intervention, $\chi^{2}$ Chi-squared

\begin{tabular}{|c|c|}
\hline Study or Subgroup & Mean Difference \\
\hline Dumortier et al. [14] & $0.31[-0.01,0.63]$ \\
\hline Watkins et al. [15] & $0.03[-0.23,0.29]$ \\
\hline Gomes et al. [16] & $-0.07[-0.17,0.03]$ \\
\hline Irving et al. [17] A & $0.17[-0.11,0.45]$ \\
\hline Irving et al. [17] B & $0.09[-0.22,0.40]$ \\
\hline Tjønna et al. [18] A & $0.26[-0.03,0.55]$ \\
\hline Tjønna et al. [18] B & $0.22[-0.06,0.50]$ \\
\hline Stensvold et al. [21] & $-0.04[-0.50,0.42]$ \\
\hline Balducci et al. [20] & $0.07[0.04,0.10]$ \\
\hline Total $(95 \% \mathrm{Cl})$ & $0.06[0.03,0.09]$ \\
\hline $\begin{array}{l}\text { Heterogeneity: } \chi^{2}=1 \\
\text { Test for overall effect: }\end{array}$ & $\begin{array}{l}=0.11) ; I^{2}=38 \% \\
0.0001)\end{array}$ \\
\hline
\end{tabular}

Fig. 5 Average net changes and corresponding 95\% confidence intervals for HDL-C. Tjønna et al. [18] $A$ and $B$ represents moderate continuous training programme and aerobic interval training programme, respectively; and Irving et al. [17] $A$ and $B$ represents high-

Finally, none of the combined exercise studies found a statistically significant effect on triglycerides, SBP or DBP.

\subsection{Secondary Outcomes: Effect of Dynamic \\ Endurance Exercise on Other Cardiovascular \\ Risk Factors}

As shown in Table 3, dynamic endurance training also positively affected other blood lipids (LDL-C, total cholesterol), some anthropometric characteristics (body
Mean Difference

IV, Fixed, $95 \% \mathrm{Cl}$

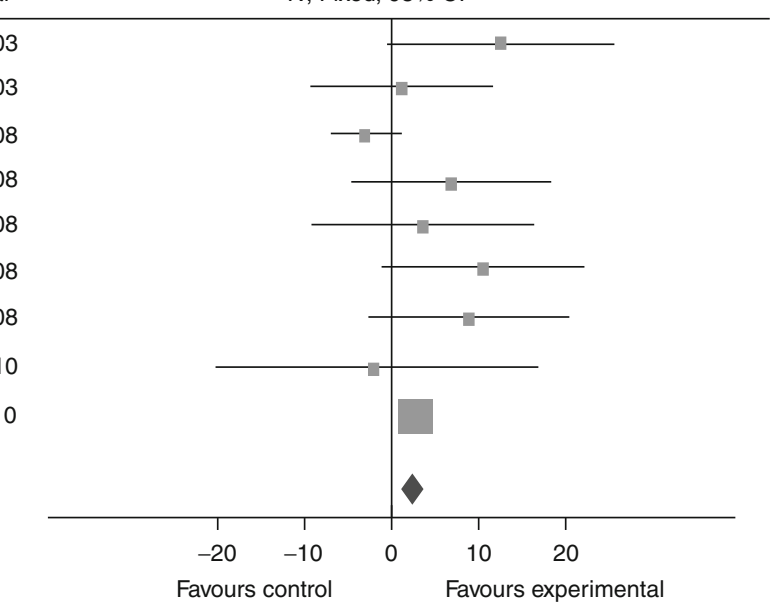

intensity training and low-intensity training, respectively. $C I$ confidence intervals, $d f$ degrees of freedom, $I V$ intervention, $\chi^{2}$ Chisquared

weight, BMI) and resulted in a significant increase of $\dot{V} \mathrm{O}_{2 \text { peak }}$ with $19.3 \%$ compared with controls.

\subsection{Publication Bias}

Funnel plots did not show any significant publication bias for all of the primary and secondary outcomes, meaning that there was no asymmetric relationship between treatment effects and study size (data not shown). 


\begin{tabular}{lcc} 
& $\begin{array}{c}\text { Mean Difference } \\
\text { IV, Fixed, 95\% Cl }\end{array}$ & Year \\
\hline Study or Subgroup & $-0.54[-1.54,0.46]$ & 2003 \\
\hline Dumortier et al. [14] & $0.17[-0.69,1.03]$ & 2003 \\
Watkins et al. [15] & $-0.16[-0.73,0.41]$ & 2008 \\
Gomes et al. [16] & $-0.73[-1.85,0.39]$ & 2008 \\
Irving et al. [17] A & $0.25[-1.29,1.79]$ & 2008 \\
Irving et al. [17] B & $-0.30[-1.77,1.17]$ & 2008 \\
Tjønna et al. [18] A & $-0.33[-2.08,1.42]$ & 2008 \\
Tjønna et al. [18] B & $0.10[-0.68,0.88]$ & 2010 \\
Stensvold et al. [21] & $-0.03[-0.19,0.13]$ & 2010 \\
Balducci et al. [20] & & \\
Total (95\% Cl) & $-0.05[-0.20,0.09]$ & \\
Heterogeneity: $\chi^{2}=3.30$, df $=8(p=0.91) ; I^{2}=0 \%$ & \\
Test for overall effect: $Z=0.72(p=0.47)$
\end{tabular}

Fig. 6 Average net changes and corresponding 95\% confidence intervals for triglycerides. Tjønna et al. [18] $A$ and $B$ represents moderate continuous training programme and aerobic interval training programme, respectively; and Irving et al. [17] $A$ and $B$ represents



high-intensity training and low-intensity training, respectively. $C I$ confidence intervals, $d f$ degrees of freedom, $I V$ intervention, $\chi^{2}$ Chi-squared

\begin{tabular}{lcc} 
& $\begin{array}{c}\text { Mean Difference } \\
\text { IV, Fixed, 95\% Cl }\end{array}$ & Year \\
\hline Study or Subgroup & $-1.59[-3.25,0.07]$ & 2003 \\
\hline Dumortier et al. [14] & $-0.29[-0.74,0.16]$ & 2003 \\
Watkins et al. [15] & $-0.33[-1.18,0.52]$ & 2008 \\
Gomes et al. [16] & $0.19[-1.11,1.49]$ & 2008 \\
Irving et al. [17] A & $-0.36[-1.46,0.74]$ & 2008 \\
Irving et al. [17] B & $-0.20[-1.62,1.22]$ & 2008 \\
Tjønna et al. [18] A & $-0.30[-1.77,1.17]$ & 2008 \\
Tjønna et al. [18] B & $-0.20[-1.70,1.30]$ & 2010 \\
Stensvold et al. [21] & & \\
& $-0.31[-0.64,0.01]$ & \\
Total (95\% Cl) & & \\
Heterogeneity: $\chi^{2}=2.92$, df $=7(p=0.89) ; I^{2}=0 \%$ \\
Test for overall effect: $Z=1.90(p=0.06)$
\end{tabular}

Fig. 7 Average net changes and corresponding 95\% confidence intervals for plasma glucose. Tjønna et al. [18] $A$ and $B$ represents moderate continuous training programme and aerobic interval training programme, respectively; and Irving et al. [17] $A$ and $B$ represents

\section{Discussion}

The main findings of this meta-analysis suggest that in patients with the MetS, dynamic endurance training is associated with favourable effects on most cardiovascular risk factors related to the MetS, that is WC, HDL-C, SBP and DBP. Our results further demonstrate that in these patients dynamic endurance training also favourably affects other important cardiovascular risk factors including LDL-C, total cholesterol, BMI and $\dot{V} \mathrm{O}_{2 \text { peak }}$.

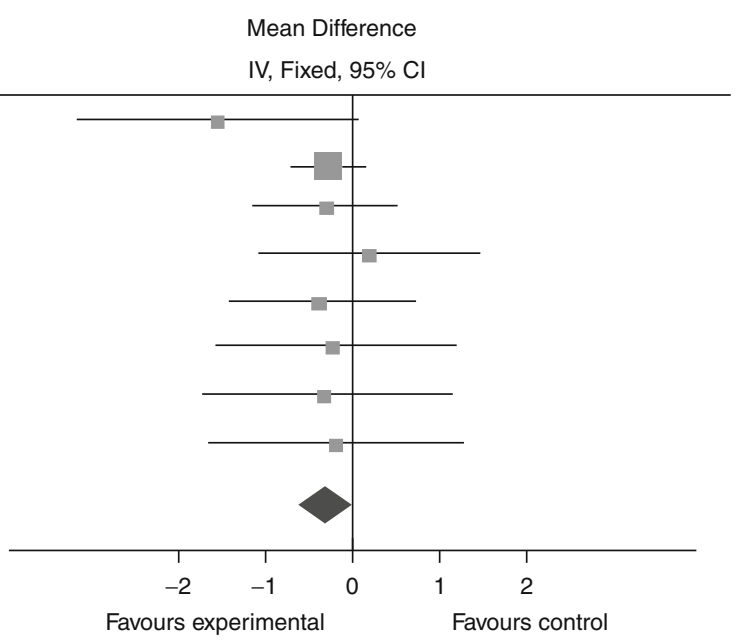

high-intensity training and low-intensity training, respectively. $C I$ confidence intervals, $d f$ degrees of freedom, $I V$ intervention, $\chi^{2}$ Chi-squared

It is generally accepted that we need better and more affordable prevention and treatment strategies to improve wide-scale cardiovascular health outcome and to prevent the epidemic of MetS from reaching global proportions and straining public health and the economy [18]. Exercise is a key component in the treatment of patients with the MetS and in the prevention of CVD morbidity and mortality. The results of this study are in line with previous meta-analyses and extensive reviews that focused on the effect of exercise on single risk factors in populations with different cardiovascular risk factors [4-7]. 
Table 3 Effect of dynamic endurance training on secondary outcomes

\begin{tabular}{|c|c|c|c|c|c|c|c|}
\hline Outcome & $\begin{array}{l}\text { Mean baseline } \\
\text { value }\end{array}$ & $\begin{array}{l}\text { Mean } \\
\text { effect }\end{array}$ & $95 \% \mathrm{CI}$ & Significance & $\begin{array}{l}\text { Interventions } \\
\text { (n) }\end{array}$ & $\begin{array}{l}\text { Heterogeneity } \mathrm{I}^{2} \\
(\%)\end{array}$ & $\begin{array}{l}\text { Model } \\
\text { used }\end{array}$ \\
\hline \multicolumn{8}{|l|}{ Blood lipids } \\
\hline LDL-C (mmol/L) & 3.34 & -0.38 & $-0.75,-0.01$ & $\mathrm{p}=0.05$ & 4 & 60 & $\mathrm{RE}$ \\
\hline $\mathrm{TC}(\mathrm{mmol} / \mathrm{L})$ & 5.55 & -0.53 & $-0.64,-0.42$ & $\mathrm{p}<0.001$ & 5 & 23 & FE \\
\hline \multicolumn{8}{|c|}{ Anthropometric characteristics } \\
\hline Weight (kg) & 92.06 & -3.51 & $-5.40,-1.61$ & $\mathrm{p}<0.001$ & 8 & 0 & $\mathrm{FE}$ \\
\hline BMI $\left(\mathrm{kg} / \mathrm{m}^{2}\right)$ & 32.18 & -1.65 & $-2.81,-0.48$ & $\mathrm{p}<0.01$ & 9 & 0 & $\mathrm{FE}$ \\
\hline FM (kg) & 38.73 & -1.92 & $-6.41,+2.57$ & NS & 4 & 0 & $\mathrm{FE}$ \\
\hline \multicolumn{8}{|l|}{ Glucose/insulin parameters } \\
\hline Plasma insulin $(\mathrm{mmol} / \mathrm{L})$ & 18.68 & -0.98 & -4.51 to +2.56 & NS & 4 & 0 & $\mathrm{FE}$ \\
\hline \multicolumn{8}{|l|}{ Other secondary outcomes } \\
\hline$\dot{V} O_{2 \text { peak }}(\mathrm{mL} / \mathrm{kg} / \mathrm{min})$ & 26.61 & +5.86 & $+3.03,+8.69$ & $\mathrm{p}<0.001$ & 8 & 58 & $\mathrm{RE}$ \\
\hline
\end{tabular}

$B M I$ body mass index, $C I$ confidence interval, $F E$ fixed effect model, $F M$ fat mass, $L D L-C$ low-density lipoprotein cholesterol, $N S$ nonsignificant, $R E$ random effect model, $T C$ total cholesterol, $\dot{V} O_{2 p e a k}$ peak oxygen uptake

First of all, we observed a significant improvement in measures of body composition including reduction in abdominal obesity, assessed by means of WC, body weight and BMI and a non-significant reduction in fat mass. Improvements in body composition characteristics are suggested to be associated with beneficial changes in lipids and lipoproteins through mechanisms related to insulin resistance $[23,24]$. Indeed, the results of our meta-regression show a trend $(\mathrm{p}=0.06)$ between changes in $\mathrm{WC}$ and HDL-C. In line with the meta-analysis of Kelley et al. [25], we observed significant increases in HDL-C and decreases in LDL-C and total cholesterol, without an effect on triglycerides. Wilson et al. [26] found that an HDL-C level between 41 and $46 \mathrm{mg} / \mathrm{dL}(1.06-1.19 \mathrm{mmol} / \mathrm{L})$ for men resulted in a relative risk (RR) of all-cause death of 1.27 and HDL-C levels between 23 and $44 \mathrm{mg} / \mathrm{dL}$ (0.59$1.14 \mathrm{mmol} / \mathrm{L}$ ) in an RR of 1.47 for women, compared with groups with values of more than 55 and $70 \mathrm{mg} / \mathrm{dL}$, respectively. In our meta-analysis, HDL-C levels rose from $1.05 \mathrm{mmol} / \mathrm{L}$ to $1.13 \mathrm{mmol} / \mathrm{L}$ in a sex-mixed population, still showing non-optimal HDL-C plasma levels. However, it is stated in a meta-analysis of Kelley et al. [25] that a decrease of $1 \%$ in HDL-C would be associated with an increase in the risk for coronary heart disease of $2-3 \%$. Assuming that the reverse is true, the approximate increase of $8 \%$ observed in our meta-analysis should decrease the coronary heart disease risk by $16-24 \%$.

In addition, patients with the MetS do have type 2 diabetes or at least have an increased risk for developing it. Whereas plasma insulin levels remained statistically unaltered, we observed a trend towards lower values of mean plasma glucose following dynamic endurance exercise $(p=0.06)$. Earlier, Snowling and Hopkins [27] reported in patients with type 2 diabetes significant reductions in fasting glucose, $\mathrm{HbA}_{1 \mathrm{c}}$ and insulin sensitivity after dynamic endurance training, with some evidence of small additional benefits resulting from combining endurance and resistance training. Moreover, it was suggested that the effects were somewhat larger for those with a more severe disease status, in particular for $\mathrm{HbA}_{1 \mathrm{c}}$. The lack of a significant effect on glucose-insulin dynamics in the current meta-analysis might be partly explained by the fact that the majority of participants were pre-diabetic but did not have diabetes. Indeed, the study of Balducci et al. [20] in patients with type 2 diabetes and the MetS did result in significant decreases in $\mathrm{HbA}_{1 \mathrm{c}}$ after 12 months of exercise training, which confirms our suggestion. In addition, measuring plasma glucose and plasma insulin after an oral glucose tolerance test is often a better marker of changes in glucose tolerance after an exercise or dietary intervention. In the study of Watkins et al. [15], significant decreases in $2 \mathrm{~h}$ of plasma insulin were found in the dynamic endurance exercise group but not in the control group after 26 weeks, while there were no changes in fasting glucose and fasting insulin.

Following dynamic endurance training, a mean reduction in $\mathrm{BP}$ of $7 / 5 \mathrm{mmHg}$ was achieved. These mean differences are statistically significant but more importantly, the magnitude of these differences is likely to be clinically relevant. Results from large, prospective intervention studies suggested that small reductions in resting SBP and DBP of $3 \mathrm{mmHg}$ can reduce coronary heart disease risk by $5 \%$, stroke by $8 \%$ and all-cause mortality by $4 \%$ [28].

Although the observed effect on each of the individual risk factors might seem small, when we combine all the effect sizes, that is a BP reduction to a mean of 131/ $82 \mathrm{mmHg}$, a decrease in WC to an average of $101 \mathrm{~cm}$ and for plasma glucose and triglycerides to a mean of 5.67 and 
$2.0 \mathrm{mmol} / \mathrm{L}$, respectively and an increase of HDL-C to $1.1 \mathrm{mmol} / \mathrm{L}$, a large number of patients would probably no longer be classified as having the MetS. Earlier, Katzmarzyk et al. [29] showed that $30.5 \%$ of patients (mean age 44.7 years) with the MetS at baseline, were no longer classified as having the MetS after a 20-week supervised dynamic endurance training programme. This reduction was mostly due to an improvement in triglycerides (43\%), BP (38\%) and WC (28\%) whereas beneficial effects on HDL-C and plasma glucose were seen in fewer patients (16 and 9\%, respectively). Similarly, Anderssen et al. [30] reported that $23.5 \%$ of 34 patients no longer had the MetS after an exercise intervention of 1 year. The only study included in this meta-analysis reporting on the number of patients with the MetS showed similar decreases with a $37.5 \%$ (from $8 / 8$ to $5 / 8$ ) and a $45 \%$ decrease (from $11 / 11$ to 6/11) following 16 weeks of continuous and interval training, respectively [18]. Although it is difficult to quantify exactly the overall risk reduction associated with all observed changes, these results are compatible with an overall improvement of cardiovascular risk. Moreover, the results of this meta-analysis study are supported by studies that have examined the cross-sectional relationship between physical activity and the MetS. For example, in 1298 healthy police employees of the Utrecht Police Lifestyle Intervention Fitness and Training (UPLIFT) study, average physical activity intensity, average time spent at physical activity, physical activity volume and physical fitness, were each associated with reduced odds of the MetS [31]. Taken together, the results of these studies, and those from the present meta-analysis, reinforce the notion that physical activity is an important treatment option for the MetS, as stated in Katzmarzyk et al. [29].

Finally, low aerobic capacity has been shown to be a stronger predictor of CVD and mortality compared with other established risk factors [32]. The five studies that reported on the effect of dynamic endurance training on $\dot{V} \mathrm{O}_{2 \text { peak }}$ showed a significant mean increase of $6 \mathrm{~mL} / \mathrm{kg} /$ min or $19.3 \%$. An increase of one metabolic equivalent task $\left(=3.5 \mathrm{~mL} \mathrm{O}_{2} / \mathrm{kg} / \mathrm{min}\right)$ in exercise capacity referred to an RR for all-cause death of 0.84 [33]. Earlier, physical activity and physical fitness have been shown to be inversely associated with the clustering of metabolic abnormalities [31]. With regard to physical activity, it seems that intensity and more specifically higher intensity is the main characteristic of physical activity determining its effect on the combination of CVD risk factors [31]. However, as physical fitness exerted greater effects [31], this suggests that in daily practice physical activity should preferably increase physical fitness to maximize its effect on the prevention of the MetS. This might most likely be achieved by exercise at higher intensity [31]. Given the lack of adequate reporting of training characteristics, we were unable to investigate the effect of intensity in this meta-analysis. A considerable number of additional studies will be required to adequately discuss this aspect.

With regard to the effect of other training characteristics on cardiovascular risk factors in patients with the MetS, more research is warranted to allow for appropriate exercise prescriptions. That is, only one intervention group investigated the effect of dynamic resistance training on the clustering of cardiovascular risk factors in individuals with the MetS and found that only WC was decreased significantly [21]. In a study of Banz et al. [34], with obese subjects, the effect of dynamic resistance training also resulted in significant changes in $\mathrm{WC}$, but in no other significant beneficial cardiovascular effects. Smutok et al. [35] found significant changes in glucose and insulin responses after an oral glucose tolerance test was administered after a dynamic resistance training programme in individuals with two cardiovascular risk factors, but blood lipids and lipoproteins or BP outcomes didn't improve significantly. It seems that dynamic resistance training has potential beneficial effects on the cardiovascular risk profile, but that dynamic endurance training is more beneficial $[34,35]$. In a large meta-analysis of Cornelissen et al. [36], the effect of resistance training on BP and other cardiovascular risk factors was reviewed. They found positive effects on SBP, DBP and $\dot{V} \mathrm{O}_{2 \text { peak }}$, but no changes were seen in HDL-C, triglycerides and plasma glucose.

The effect of combined exercise on the clustering of cardiovascular risk factors in patients with MetS was discussed in two studies [20, 21]. Balducci et al. [20] concluded that combined endurance and resistance training had larger beneficial effects on upper body strength and body weight than dynamic endurance training only. No significant differences were found for the other outcome measures [20]. Stensvold et al. [21] found slightly larger benefits for the dynamic endurance training on SBP and DBP than that of combined exercise. The training responses were similar for WC, HDL-C, triglycerides and plasma [21]. However, more research is needed to investigate the potential benefits of combined training programmes.

The results of this meta-analysis should be interpreted within the context of its limitations: First, only one study fulfilling the inclusion criteria included a dynamic resistance intervention [21], and only two trials used a combined intervention of dynamic resistance training and endurance training $[20,21]$. Further research about the effect of dynamic resistance training only or in combination with dynamic endurance exercise training is warranted in patients with the MetS. Second, a sensitivity analysis demonstrated that omitting the only trial in which all 
patients had type 2 diabetes [20], the effect of exercise on DBP, HDL-C and WC were no longer significant ( $p=0.07 ; p=0.44 ; p=0.40$, respectively). The severity of the MetS risk factors or a pathological state (type 2 diabetes) can probably influence the effects of exercise training, with more severe $\mathrm{CV}$ risk factors resulting in potentially larger improvements. Third, due to the small number of study groups, a subgroup analysis for sex or medication intake was not possible. More research is needed on the effect of variables that could potentially affect the outcomes of an exercise programme, especially the effect of sex and medication. Further, the mean age of participants was 52 years with a range between 46 and 64 years; therefore it may not be possible to generalize these results for younger or older individuals with the MetS. Finally, it has been suggested that one exercise dose does not fit for all components of the MetS and that recommendations should vary regarding the different risk factors [37]. Therefore, it is necessary to strike a balance for the most optimal exercise programme to improve the cluster of cardiovascular risk factors in patients with the MetS.

\section{Conclusion}

It can be concluded that exercise interventions have beneficial effects on most of the cardiovascular risk factors in patients with the MetS, but further research is needed to expand the knowledge and to strengthen the results found in this meta-analysis.

Acknowledgements No potential conflicts of interest directly relevant to this content of this article were reported. Véronique A. Cornelissen is supported as a Postdoctoral Fellow by Research Foundation Flanders (F.W.O.). Prof. Luc Vanhees is the holder of the faculty chair 'Lifestyle and Health' at the University of Applied Sciences, Utrecht, the Netherlands; Nele Pattyn is a doctoral researcher at the KU Leuven, Department of Rehabilitation Sciences; Saeed R. Toghi Eshghi was a Master's student at KU Leuven, at the time of the preparation of this article.

Open Access This article is distributed under the terms of the Creative Commons Attribution Noncommercial License which permits any noncommercial use, distribution, and reproduction in any medium, provided the original author(s) and the source are credited.

\section{References}

1. Grundy SM, Cleeman JI, Daniels SR, et al. Diagnosis and management of the metabolic syndrome: an American Heart Association/National Heart, Lung, and Blood Institute Scientific Statement. Circulation. 2005;112(17):2735-52.

2. Gami AS, Witt BJ, Howard DE, et al. Metabolic syndrome and risk of incident cardiovascular events and death: a systematic review and meta-analysis of longitudinal studies. J Am Coll Cardiol. 2007;49(4):403-14.

3. Grundy SM. Metabolic syndrome pandemic. Arterioscler Thromb Vasc Biol. 2008;28(4):629-36.

4. Whelton SP, Chin A, Xin X, et al. Effect of aerobic exercise on blood pressure: a meta-analysis of randomized, controlled trials. Ann Intern Med. 2002;136(7):493-503.

5. Cornelissen VA, Fagard RH. Effects of dynamic aerobic endurance training on blood pressure, blood pressure-regulating mechanisms and cardiovascular risk factors. Hypertension. 2005; 46(4):667-75.

6. Kelley GA, Kelley KS. Aerobic exercise and lipids and lipoproteins in men: a meta-analysis of randomized controlled trials. J Mens Health Gend. 2006;3(1):61-70.

7. Thomas D, Elliot EJ, Naughton GA. Exercise for type 2 diabetes mellitus. Cochrane Database Syst Rev. 2006;3:CD002968.

8. Alberti KG, Zimmet PZ. Definition, diagnosis and classification of diabetes mellitus and its complications: part 1. Diagnosis and classification of diabetes mellitus provisional report of a WHO consultation. Diabet Med. 1998;15(7):539-53.

9. National Cholesterol Education Program (NCEP). Expert Panel on detection evaluation, and treatment of high blood cholesterol in adults (Adult Treatment Panel III). Third report of the National Cholesterol Education Program (NCEP) Expert Panel on detection, evaluation, and treatment of high blood cholesterol in adults (Adult Treatment Panel III) Final report. Circulation. 2002; 106(25):3143-421.

10. Alberti KG, Zimmet P, Shaw J. IDF Epidemiology Task Force Consensus Group. The metabolic syndrome: a new worldwide definition. Lancet. 2005;366(9491):1059-62.

11. Physiotherapy Evidence Database. PEDro scale (online). http://www.pedro.org.au/english/downloads/pedro-scale/. Accessed 9 Dec 2011.

12. De Morton NA. The PEDro scale is a valid measure of the methodological quality of clinical trials: a demographic study. Aust J Physiother. 2009;55(2):129-33.

13. Maher CG, Sherrington C, Herbert RD, et al. Reliability of the PEDro scale for rating quality of randomized controlled trials. Phys Ther. 2003;83(8):713-21.

14. Dumortier M, Brandou F, Perez-Martin A, et al. Low intensity endurance exercise targeted for lipid oxidation improves body composition and insulin sensitivity in patients with the metabolic syndrome. Diabetes Metab. 2003;29(5):509-18.

15. Watkins LL, Sherwood A, Feinglos M, et al. Effects of exercise and weight loss on cardiac risk factors associated with syndrome X. Arch Intern Med. 2003;163(16):1889-95.

16. Gomes VA, Casella-Filho A, Chagas ACP, et al. Enhanced concentrations of relevant markers of nitric oxide formation after exercise training in patients with metabolic syndrome. Nitric Oxide. 2008;19(4):345-50.

17. Irving BA, Davis CK, Brock DW, et al. Effect of exercise training intensity on abdominal visceral fat and body composition. Med Sci Sports Exerc. 2008;40(11):1863-72.

18. Tjønna AE, Lee SJ, Rognmo $\varnothing$, et al. Aerobic interval training versus continuous moderate exercise as a treatment for the metabolic syndrome: a pilot study. Circulation. 2008;118(4): 346-54.

19. Irving BA, Weltman JY, Patrie JT, et al. Effect of exercise training intensity on nocturnal growth hormone secretion in obese adults with the metabolic syndrome. J Clin Endocrinol Metab. 2009;94(6):1979-86.

20. Balducci S, Zanuso S, Nicolucci A, et al. Anti-inflammatory effect of exercise training in subjects with type 2 diabetes and the metabolic syndrome is dependent on exercise modalities and independent of weight loss. Nutr Metab Cardiovasc Dis. 2010; 20(8):608-17. 
21. Stensvold D, Tjønna AE, Skaug EA, et al. Strength training versus aerobic interval training to modify risk factors of metabolic syndrome. J Appl Physiol. 2010;108(4):804-10.

22. Tjønna AE, Rognmo Ø, Bye A, et al. Time course of endothelial adaptation after acute and chronic exercise in patients with metabolic syndrome. J Strength Cond Res. 2011;25(9):2552-8.

23. Dattilo AM, Kris-Etherton PM. Effects of weight reduction on blood lipids and lipoproteins: a meta-analysis. Am J Clin Nutr. 1992;56(2):320-8.

24. Rashid S, Genest J. Effect of obesity on high-density lipoprotein metabolism. Obesity (Silver Spring). 2007;15(12):2875-88.

25. Kelley GA, Kelley KS, Tran ZV. Exercise, lipids, and lipoproteins in older adults: a meta-analysis. Prev Cardiol. 2005;8(4): 206-14.

26. Wilson PW, Abbott RD, Castelli WP. High density lipoprotein cholesterol and mortality: the Framingham Heart Study. Arteriosclerosis. 1988;8(6):737-41.

27. Snowling NJ, Hopkins WG. Effects of different modes of exercise training on glucose control and risk factors for complications in type 2 diabetic patients. Diabetes Care. 2006;29(11):2518-27.

28. Lewington S, Clarke R, Qizilbash N, et al. Prospective Studies Collaboration. Age-specific relevance of usual blood pressure to vascular mortality: a meta-analysis of individual data for one million adults in 61 prospective studies. Lancet. 2002;360(9349): 1903-13.

29. Katzmarzyk PT, Leon AS, Wilmore JH, et al. Targeting the metabolic syndrome with exercise: evidence from the HERITAGE Family Study. Med Sci Sports Exerc. 2003;35(10): 1703-9.

30. Anderssen SA, Carroll S, Urdal P, et al. Combined diet and exercise intervention reverses the metabolic syndrome in middle- aged males: results from the Oslo Diet and Exercise Study. Scand J Med Sci Sports. 2007;17(6):687-95.

31. Sassen B, Cornelissen VA, Kiers H, et al. Physical fitness matters more than physical activity in controlling cardiovascular disease risk factors. Eur J Cardiovasc Prev Rehabil. 2009;16(6):677-83.

32. Myers J, Prakash M, Froelicher V, et al. Exercise capacity and mortality among men referred for exercise testing. N Engl J Med. 2002;346(11):793-801.

33. Laukkanen JA, Rauramaa R, Salonen JT, et al. The predictive value of cardiorespiratory fitness combined with coronary risk evaluation and the risk of cardiovascular and all-cause death. J Intern Med. 2007;262(2):263-72.

34. Banz WJ, Maher MA, Thompson WG, et al. Effects of resistance versus aerobic training on coronary artery disease risk factors. Exp Biol Med. 2003;228(4):434-40.

35. Smutok MA, Reece C, Kokkinos PF, et al. Aerobic versus strength training for risk factor intervention in middle-aged men at high risk for coronary heart disease. Metabolism. 1993;42(2): 177-84.

36. Cornelissen VA, Fagard RH, Coeckelberghs E, et al. Impact of resistance training on blood pressure and other cardiovascular risk factors: a meta-analysis of randomized, controlled trials. Hypertension. 2011;58(5):950-8.

37. Vanhees L, Geladas N, Hansen D, et al., on behalf of the writing group of the EACPR. Importance of characteristics and modalities of physical activity and exercise in the management of cardiovascular health in individuals with cardiovascular risk factors: recommendations from the EACPR (part II). Eur J Cardiovasc Prev Rehabil (epub 30 Nov 2011). 